\title{
Comparison of Clinical Symptoms of Assumed vs. Actual Uterine Fibroids - Symptoms Described by Patients and Ultrasound Findings
}

\author{
Vergleich der klinischen Symptomatik eines vermuteten \\ vs. eines tatsächlichen Uterus myomatosus - \\ Symptomangaben der Patientin und Ultraschallbefund
}

(두)(1) (요 $\ominus$

Authors

Nina Isabelle Knudsen ${ }^{1}$, Klaus-D. Wernecke ${ }^{2}$, Heribert Kentenich ${ }^{3}$, Matthias David ${ }^{1}$

\section{Affiliations}

1 Charité Universitätsmedizin Berlin, Campus Virchow Klinikum, Klinik für Gynäkologie, Berlin, Germany

2 SOSTANA GmbH, Berlin, Germany

3 Fertility Center Berlin, Berlin, Germany

Key words

fibroids, sonography, dysmenorrhea, dyspareunia, premenstrual pain

Schlüsselwörter

Myome, Sonografie, Dysmenorrhö, Dyspareunie, prämenstruelle Schmerzen

received $\quad 12.2 .2019$

revised $\quad 2.8 .2019$

accepted 2.8.2019

\section{Bibliography}

DOI https://doi.org/10.1055/a-0991-0105

Published online 30.10.2019 | Geburtsh Frauenheilk 2020; 80: 316-323 @ Georg Thieme Verlag KG Stuttgart .

New York | ISSN 0016-5751

Correspondence

Prof. Dr. med. Matthias David

Klinik für Gynäkologie, Campus Virchow-Klinikum,

Charité - Universitätsmedizin Berlin

Augustenburger Platz 1, 13353 Berlin, Germany

matthias.david@charite.de

(日)

Deutsche Version unter:

https://doi.org/10.1055/a-0991-0105

\section{ABSTRACT}

Purpose How many women assume that they have fibroids but are found not to have fibroids on ultrasound examination? How severe are the physical symptoms reported by these women compared to the symptoms reported by women with actual uterine fibroids? Are the symptoms more severe if the patient believes that she has at least one relatively large (dominant) fibroid or more than 3 fibroids?

Material and Methods A total of 1548 patients completed an anonymous questionnaire in which they were asked about the number of their fibroids, dysmenorrhea and premenstrual symptoms, dyspareunia and bleeding disorders (using a numerical analog scale between $0-10$ ). The questionnaire was administered in a hospital-based fibroid clinic. The information provided by the patients was then compared with transvaginal or abdominal ultrasound findings. The symptoms reported by women with and without fibroid(s) were compared. Results 1045 out of 1548 patients fulfilled the study's inclusion criteria. Contrary to the information they provided, no fibroid(s) were detected in 6\% (62 of 1045 patients) of patients on ultrasound examination. Of these women, $87 \%$ had dysmenorrhea, $79 \%$ had premenstrual pain and $57 \%$ reported dyspareunia. The severity of the symptoms was found not to be associated with the assumed size or number of fibroid(s). There was no significant difference in the pain reported by women without and by women with fibroids. Reporting a feeling of strong pressure on the bladder (OR: 1.18) or abdomen (OR: 1.12) or constipation (OR: 1.16) increased the likelihood of detecting a fibroid on ultrasound investigation.

Conclusions The presence of manifest symptoms (dysmenorrhea, dyspareunia, premenstrual pain, bleeding disorders) does not allow conclusions to be made about the number or size of fibroids or about which therapy is indicated. Even an erroneous assumption about the presence of fibroids may result in patients experiencing symptoms.

\section{ZUSAMMENFASSUNG}

Fragestellung Wie viele Frauen nehmen Myome bei sich an, haben aber im Ergebnis der ärztlich-sonografischen Untersuchung keine Myome? In welcher Stärke treten Beschwerden bei diesen Frauen im Vergleich zu Myompatientinnen trotzdem auf? Sind diese Beschwerden stärker ausgeprägt, wenn 
die Patientin glaubte, dass sie mindestens ein relativ großes (dominantes) Myom oder über 3 Myome hat?

Material und Methodik 1548 Patientinnen beantworteten einen anonymen Fragebogen mit Angabe ihrer Myomanzahl, Dysmenorrhö und prämenstruellen Beschwerden, Schmerzen beim Geschlechtsverkehr sowie Blutungsstörungen (numerische Analogskala 0-10) in einer Klinik-Myomsprechstunde. Anschließend erfolgte eine Gegenüberstellung der Patientinnenangaben mit dem transvaginalen bzw. ggf. abdominellen Ultraschallbefund. Die Beschwerdeangaben von Frauen mit und ohne Myom(en) wurden verglichen.

Ergebnisse 1045 von 1548 Patientinnen entsprachen den Einschlusskriterien. Bei 6\% (62 der 1045 Patientinnen) ließ sich entgegen ihren Angaben in der durchgeführten sonografischen Untersuchung kein Myom feststellen. Von diesen
Frauen hatten 87\% Dysmenorrhö, 79\% prämenstruelle Schmerzen und 57\% Dyspareunie. Die Beschwerdeausprägung zeigte keinen Zusammenhang mit der angenommenen Myomgröße oder -anzahl. Es zeigte sich kein signifikanter Unterschied in den Schmerzangaben von den befragten Frauen ohne und mit Myom(en). Die Angabe von starkem Druckgefühl auf die Blase (OR 1,18) oder im Unterbauch (OR 1,12) bzw. Obstipation (OR 1,16) erhöhten die Wahrscheinlichkeit, dass sonografisch ein Myom nachgewiesen werden konnte.

Schlussfolgerungen Durch die Symptomausprägung (Dysmenorrhö, Dyspareunie, prämenstruelle Schmerzen, Blutungsstörungen) kann nicht auf die Anzahl oder die Größe von Myomen geschlossen oder eine Therapie abgeleitet werden. Bereits die Fehlannahme von Myomen kann bei Patientinnen zu Symptomen führen.

\section{Introduction}

Symptoms frequently reported in gynecological practice include dyspareunia, premenstrual pain, dysmenorrhea and bleeding disorders, which may sometimes be due to the presence of uterine fibroids. Uterine fibroids are the most common benign uterine tumors and occur in around $20-40 \%$ of women of child-bearing age [1]. Between $20-50 \%$ of women with fibroids present with symptoms requiring treatment [2]. Previous studies have shown that patients can have very different perceptions of pain, even when the clinical picture of the fibroid is the same [3-6]. Pain must therefore be considered as psychosomatic as the presence of fibroids is not necessarily associated with pain or other symptoms. Self-perception determines the patient's perception of "disease" and it is important that this is recorded. Reported physical symptoms of uterine fibroids include heavy, prolonged menstrual bleeding, dysmenorrhea, dyspareunia, abdominal pressure and foreign body sensation in the pelvis and a sensation of pressure on the bladder $[7,8]$. In addition to hypermenorrhea, fibroid-related pain is the most common problem reported by affected patients [9]. In contrast to premenstrual pain and dyspareunia, the severity of dysmenorrhea depends on the location and size of the dominant fibroid [9]. Fibroid-related symptoms affect every aspect of life of affected women and have a moderate to strong impact on their quality of life $[4,10]$. While typical bleeding symptoms have the greatest impact, other potential symptoms can also have a significant and verifiable impact on quality of life [11]. The results of a systematic review carried out by Jones et al. showed that the negative impact of benign gynecological disease on quality of life is greater when chronic pelvic pain is one of the primary presenting symptoms [12]. Anxiety may additionally develop, depending on the individual woman's life situation [1315]. However, patients who do not have fibroids may also have abdominal pain, but from other causes [16]. The differential diagnosis for abdominal pain includes adenomyosis and endometriosis. Affected patients often report a combination of symptoms including pain in the pelvic area, dysmenorrhea, dyspareunia and menorrhagia [17]. Transvaginal ultrasound is currently the primary imaging modality used to diagnose adenomyosis [18]. En- dometriosis cannot be excluded by transvaginal ultrasound examination. Diagnostic laparoscopy is the modality of choice to diagnose endometriosis $[19,20]$. (Vaginal) sonography is the most commonly used and suitable procedure for the detection, imaging and characterization of fibroids [21,22]. Some working groups have reported that MRI and sonography have a comparable sensitivity and specificity with regard to diagnosing fibroids [23-25]. Stupin et al. found a relatively good agreement between the number of fibroids which the patient assumed to be present and the actual findings on ultrasound. However, the level of information about the (approximately correct) size of the fibroid was significantly lower [26].

The subjectivity of complaints reported by patients plays an important role in routine medical care. Incorrect information (caused, for example, by communication misunderstandings during medical consultations or by the patient's internet research) can be the cause of a discrepancy between subjectively assumed disease and actual ultrasound findings. It is not always easy to explain this coherently and comprehensibly to the patient. No study to date has evaluated possible associations between how symptoms manifest und an erroneous assumption by the patient that she has fibroids. This study therefore aims to look in more detail at two particular aspects which arise during medical consultations for fibroid symptoms:

1. The (non-) agreement between fibroid symptoms reported by patients and the actual fibroid findings found on gynecological ultrasound examinations, and

2. The range of symptoms (dysmenorrhea, premenstrual pain and dyspareunia) reported by a particular subgroup of patients in whom, contrary to their own assumptions, no fibroids were detected on ultrasound.

The data of this patient cohort are compared with the symptoms reported by a large group of patients with fibroids, and the possible consequences for clinical practice are discussed. 


\section{Method}

\section{Inclusion criteria and questionnaire}

A self-developed questionnaire with 28 questions was used. The questionnaire was given to all patients prior to their consultation at the fibroid clinic of the Gynecology Department of Charité, University Hospital Berlin, Campus Virchow-Klinikum, together with other questionnaires about their medical history after patients had been informed about the study. Completion of the questionnaire was voluntary. The women were referred either for fibroidrelated symptoms or to plan surgical or non-surgical therapy or to obtain a second opinion. Inclusion criteria: all patients who were at least 18 years old and were linguistically able - either on their own or with the help of accompanying family members - to complete the questionnaire, which was only available in German. Additional inclusion criteria were unambiguous ultrasound findings and details provided by the patient on the questionnaire about the assumed number and size of fibroids. Exclusion criteria were ultrasound findings indicating adenomyosis.

The questionnaire was divided into three parts:

1. A general medical history part (including previous pregnancies, existing wish to have children, other diseases or illnesses, current and previous medication),

2. Fibroid-specific information (known since when, number, size) and information about the patient's menstruation (regularity of periods, mid-cycle bleeding, duration, start of menopause), and

3. Information about symptoms, using a Likert scale (0-10, minimum 0 and maximum 10) to classify the severity of menstrual flow, premenstrual pain and dyspareunia, dysmenorrhea, back pain, pressure on the bladder, abdominal pressure/foreign body sensation in the abdomen, and bloating/constipation.

The questionnaire also included a free text box where patients could include further information about symptoms which they ascribed to their fibroids. Every patient then had an ultrasound examination, which was carried out in all cases by the same experienced investigator (M.D.) and using the same ultrasound unit (Combison 420 Ultrasound, Kretztechnik, Austria). Examinations generally consisted of vaginal sonography (7.5 MHz transducer); if the uterus was very large, the examination additionally included abdominal ultrasound or was carried out using only abdominal ultrasound ( $5 \mathrm{MHz}$ transducer). The location and sizes of the three largest (dominant) fibroids were documented with photography and included in a schematic drawing of the uterus.

\section{Statistical analysis}

Statistical analysis of the data was done using the software package IBM $^{\circledR}$ SPSS $^{\circledR}$ Statistics, Version 25, (C) Copyright 1989, 2016 SPSS Inc., IBM Company. The results were recorded as frequencies or mean or median values, depending on the scale used for the observed values. In addition to the number of fibroids per patient detected on ultrasound, the subjective number of fibroids which the patient assumed to be present was also recorded. Possible correlations were analyzed using the kappa coefficient for categorical data. After the ultrasound examination, the entire patient co- hort was divided into two subgroups for further analysis according to the verified ultrasound findings (no fibroids versus fibroids). The 11 steps of the scale were summarized into four categories of symptoms: 0 = no complaints or pain, 1-3 = mild discomfort, 4-7 = moderate discomfort, $8-10=$ severe discomfort. The differences in age between women without fibroids and women with fibroids were analyzed using Mann-Whitney U-test and the differences in discomfort were evaluated using Chi-square test. A logistic regression analysis was carried out using the effect variable "fibroid on ultrasound" vs. "no fibroid on ultrasound" (dependent variable) and the influencing variables "back pain", "pressure on the bladder”, "abdominal pressure”, "constipation”, “dyspareunia" and "menstrual pain" (logistic regression variables) with purposeful stepwise selection of variables. The level of significance was defined as a p-value of $<0.05$. Given the study's explorative nature, variables were not adjusted for multiple testing.

\section{Ethics vote and data protection}

The study was approved by the ethics commission of Charité Universitätsmedizin Berlin. The study complies with the Charité's updated charter on the ensuring good scientific practice [27] and the provisions of Berlin's data protection law.

\section{Results}

A total of consecutive 1548 patients completed the questionnaire when attending the hospital's fibroid clinic prior to their medical consultation. No fibroids were found on ultrasound in $7.2 \%$ ( $n=111)$ of these patients. $32.5 \%(n=503)$ of the women did not state the number of fibroids they assumed they had, so that $67.5 \%$ (1045) of the women who completed the questionnaire were ultimately included in the study in accordance with the study's inclusion and exclusion criteria. This group included 62 patients (6\%) who assumed that they had fibroids but had no detectable fibroids on (transvaginal and abdominal) ultrasound examination. This patient cohort did not include any women with sonographic indications of adenomyosis or ovarian cysts suspicious for endometriosis. There was sufficient correlation according to the Kappa coefficient ( $p=0.047$ ) between ultrasound findings and subjective assumptions about the number of fibroids for the categories " 0 " to " $>3$ " fibroids and a very good correlation for the categories " 1 " to "> 3 " fibroids $(p<0.0001)$. The group with no detectable fibroids on ultrasound is referred to hereinafter as the "No fibroid" subgroup and discussed further below.

\section{Patients with no detectable fibroids}

In the "No fibroid" subgroup, $71 \%$ of patients $(n=44)$ were older than 40 and $29 \%(n=18)$ under 40 years of age. $>$ Table 1 provides additional details of these patients' medical history. To evaluate their reported pain, the information provided by the patients was summarized into four subgroups on a numerical analog scale (0-10): 0 = no pain, $1-3=$ slight pain, $4-7=$ moderate pain, $8-10$ = severe pain. The frequency with which dysmenorrhea and premenstrual pain was reported (63 and 65\%, resp.) was roughly the same for those patients who reported slight or those who reported moderate discomfort (= severity of symptoms: from 1 to $7)$. $23 \%(n=12)$ of patients classed the severity of their dysmen- 


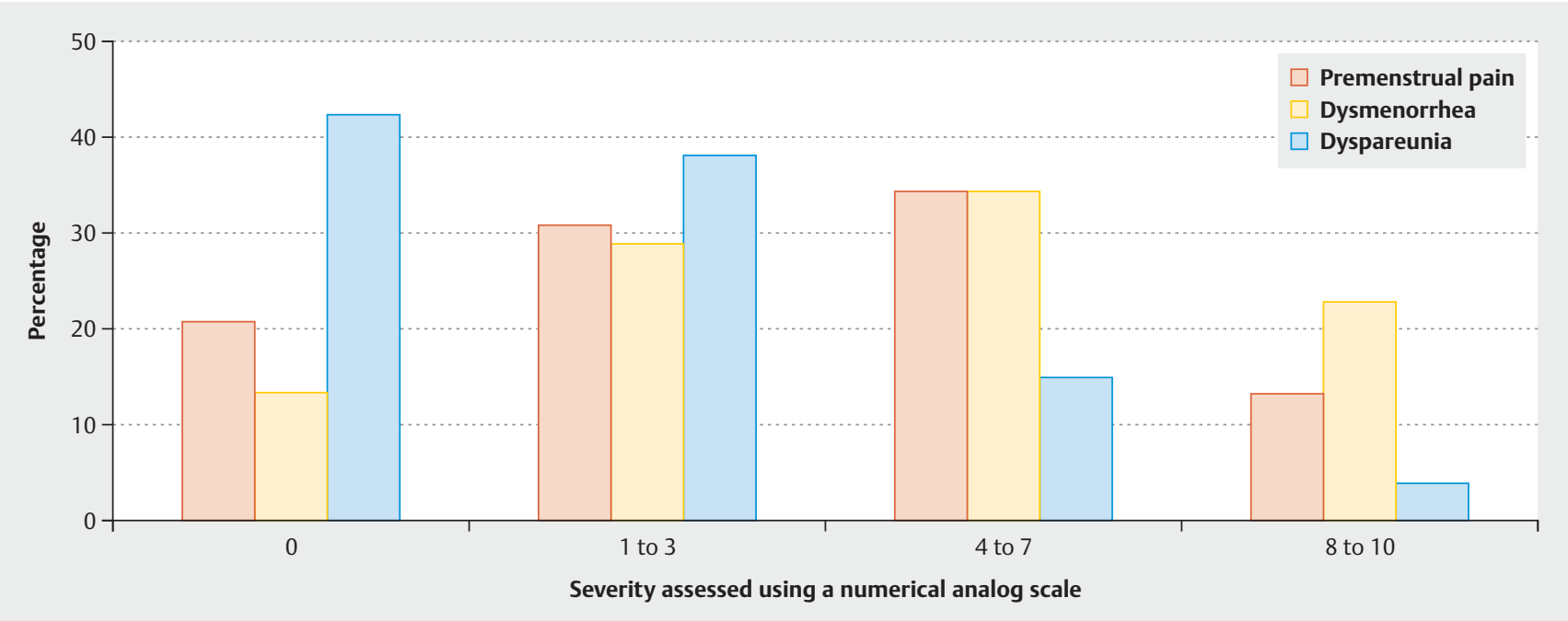

- Fig. 1 Pain reported by patients with no detectable fibroids. Pain was scored using an 11-step scale and then grouped into four larger categories according to severity of symptoms: $0=$ no discomfort or pain, $1-3=$ mild discomfort, $4-7=$ moderate discomfort, $8-10=$ severe discomfort.

- Table 1 Information provided by women with no detectable fibroids on ultrasound $(n=62)$ (percentages have been rounded to whole numbers).

\begin{tabular}{|l|c|}
\hline Age & $\begin{array}{c}43.5 \text { years (median) } \\
22-52 \text { years (range) }\end{array}$ \\
\hline Wish to have children & \\
\hline - yes & $32 \%(18)$ \\
\hline - no & $68 \%(39)$ \\
\hline & 5 missing \\
\hline Prior pregnancies (medical history) & \\
\hline - yes & $66 \%(40)$ \\
\hline - no & $34 \%(21)$ \\
\hline & 1 missing \\
\hline Assumed number of fibroids & \\
\hline - 1 & $45 \%(28)$ \\
\hline - 2 & $27 \%(17)$ \\
\hline - 3 & $10 \%(6)$ \\
\hline - 4 & $18 \%(11)$ \\
\hline - >4 & 0 \\
\hline
\end{tabular}

orrhea as very severe (scale values 8 to 10$) .43 \%(n=20)$ of women stated that they had no dyspareunia and $38 \%(n=18)$ reported slight dyspareunia ( $\vee$ Fig. 1).

To determine the potential impact of the assumed size or number of fibroids, the women were requested to write this information on the questionnaire. No significant association was found between the severity of symptoms and the assumed fibroid size (grouped into $<8 \mathrm{~cm}$ and $\geq 8 \mathrm{~cm}$ ) on the one hand and the assumed number of fibroids (grouped into 1-3 fibroids and $>3$ fibroids) on the other.

\section{Patients with detectable fibroids}

Ultrasound examinations found at least one fibroid in 983 women who reported the number of fibroids they assumed they had. One fibroid was found in $60 \%$ (588) of women, 2 or 3 fibroids were detected in $30 \%$ (297) of women, and 10\% (98) of women had more than 3 fibroids or a myomatous uterus ( $\triangleright$ Table 2 ). As already noted for the "No fibroid" subgroup, no association was found between symptoms and the assumed fibroid size or number of fibroids in the group of women with verifiable fibroids. Patients who assumed that they had 1-3 fibroids reported more pain during sexual intercourse than women with $>3$ assumed fibroids $(p=0.013)$. However, it should be noted that when the responses were evaluated, the number of women with 1-3 assumed fibroids $(n=866)$ was significantly greater than the number of women with $>3$ fibroids $(n=47)$.

\section{Comparison of groups with and without detectable fibroids}

Overall the "No fibroid" subgroup did not differ significantly from women with 1 fibroid, 2-3 fibroids or several fibroids/myomatous uterus in terms of reported premenstrual pain, dysmenorrhea and dyspareunia ( $\vee$ Table 3 ). $\vee$ Fig. 2 shows the pain reported by women with and without fibroids detectable on ultrasound examination.

Logistic regression analysis ( $n=1419$ ) was carried out to determine significant influencing variables, with patients classified either into Group A "Fibroid detected on ultrasound" or Group B "No fibroid detected on ultrasound". The variables listed in $>$ Table 4 were the result of a stepwise selection of variables out of a larger group of available variables. This revealed that when the pain level increased by one unit (Likert scale 1-10, minimum 1 to maximum 10), the probability that the patient would be classified as Group A decreased by $18 \%$ if the patient reported back pain, but increased by $18 \%$ if the patient reported pressure on the bladder, increased by $12 \%$ if the patient reported abdominal pressure 
- Table 2 Number of patients with varying numbers of fibroids according to the patient's self-assessment versus ultrasound findings.

\begin{tabular}{|c|c|c|c|c|c|}
\hline & & \multicolumn{3}{|c|}{ Number of patients with varying numbers fibroids verifiable on ultrasound } & \multirow[t]{2}{*}{ Total } \\
\hline & & 1 & 2 or 3 & $>3$ or myomatous uterus & \\
\hline \multirow{5}{*}{$\begin{array}{l}\text { Number of patients with } \\
\text { reported or assumed } \\
\text { number of fibroids }\end{array}$} & 1 & 461 & 72 & 24 & 585 \\
\hline & 2 & 78 & 132 & 19 & 246 \\
\hline & 3 & 37 & 75 & 25 & 143 \\
\hline & 4 & 9 & 12 & 16 & 48 \\
\hline & $>4$ & 3 & 6 & 14 & 23 \\
\hline Total & & 588 & 297 & 98 & 1045 \\
\hline
\end{tabular}

- Table 3 Level of pain reported using a Likert scale (0-10) ( ${ }^{*}$ percentages rounded to whole numbers).

\begin{tabular}{|c|c|c|c|c|c|c|c|c|c|c|c|c|}
\hline \multirow{2}{*}{$\begin{array}{l}\text { Number } \\
\text { of fibroids }\end{array}$} & \multicolumn{4}{|c|}{ Premenstrual pain } & \multicolumn{4}{|c|}{ Dysmenorrhea } & \multicolumn{4}{|c|}{ Dyspareunia } \\
\hline & 0 & $1-3$ & $4-7$ & $8-10$ & 0 & $1-3$ & $4-7$ & $8-10$ & 0 & $1-3$ & $4-7$ & $8-10$ \\
\hline None (\%) & 21 & 31 & 35 & 14 & 14 & 29 & 35 & 23 & 43 & 38 & 15 & 4 \\
\hline$n$ & 52 & & & & 52 & & & & 47 & & & \\
\hline $1(\%)$ & 28 & 38 & 26 & 8 & 20 & 32 & 32 & 16 & 54 & 29 & 14 & 3 \\
\hline$n$ & 560 & & & & 561 & & & & 547 & & & \\
\hline 2 or $3(\%)$ & 25 & 39 & 26 & 10 & 20 & 34 & 24 & 22 & 52 & 32 & 13 & 3 \\
\hline$n$ & 287 & & & & 285 & & & & 274 & & & \\
\hline$>3(\%)$ & 29 & 33 & 30 & 9 & 22 & 38 & 28 & 13 & 42 & 34 & 19 & 5 \\
\hline $\mathrm{n}$ & 98 & & & & 96 & & & & 92 & & & \\
\hline
\end{tabular}

- Table 4 Fibroid on ultrasound vs. no fibroid on ultrasound - influencing variables associated with a higher probability of detecting a fibroid on ultrasound $(n=1419)$.

\begin{tabular}{|c|c|c|c|c|c|c|}
\hline \multirow[t]{2}{*}{ Symptoms reported by the patient ${ }^{a}$} & \multirow[t]{2}{*}{ B } & \multirow[t]{2}{*}{ S.E. } & \multirow[t]{2}{*}{ Sig. } & \multirow{2}{*}{$\begin{array}{l}\text { Odds ratio } \\
\text { (OR) }\end{array}$} & \multicolumn{2}{|c|}{$95 \% \mathrm{Cl}^{\mathrm{b}}$ for OR } \\
\hline & & & & & Lower limit & Upper limit \\
\hline Back pain & -0.205 & 0.038 & 0.000 & 0.815 & 0.756 & 0.879 \\
\hline Pressure on the bladder & 0.161 & 0.060 & 0.007 & 1.175 & 1.045 & 1.321 \\
\hline Abdominal pressure & 0.117 & 0.062 & 0.061 & 1.124 & 0.994 & 1.271 \\
\hline Constipation & 0.145 & 0.056 & 0.010 & 1.156 & 1.036 & 1.290 \\
\hline Constant & 2.406 & 0.163 & 0.000 & 11.089 & & \\
\hline \multicolumn{7}{|l|}{ a Score between 1-10 on the Likert scale } \\
\hline \multicolumn{7}{|l|}{${ }^{\mathrm{b}} \mathrm{Cl}=$ confidence interval } \\
\hline \multicolumn{7}{|c|}{$\begin{array}{l}\text { B = Regression coefficient B, S. E. = standard error, Sig. = significance, } \mathrm{OR}=\text { odds ratio. The corresponding odds ratio indicates the probability that the patient } \\
\text { will be classified into the group "fibroids detectable on ultrasound" based on individual symptoms. Stepwise selection of variables }(n=1419) \text {. }\end{array}$} \\
\hline
\end{tabular}

and increased by $16 \%$ if the patient reported constipation. In summary, this means that the greater the severity of symptoms (bladder, abdomen, constipation), the greater the likelihood that the patient had a fibroid detectable on ultrasound. This was in contrast to the results for back pain, i.e., the greater the severity of back pain reported by the patient, the greater the likelihood that no fibroid was detected on ultrasound ( $\triangleright$ Table 4 ). Reported symptoms "dysmenorrhea" $(p=0.17)$ and "dyspareunia" $(p=0.65)$ were not found to be significantly associated with the presence or absence of fibroids. 


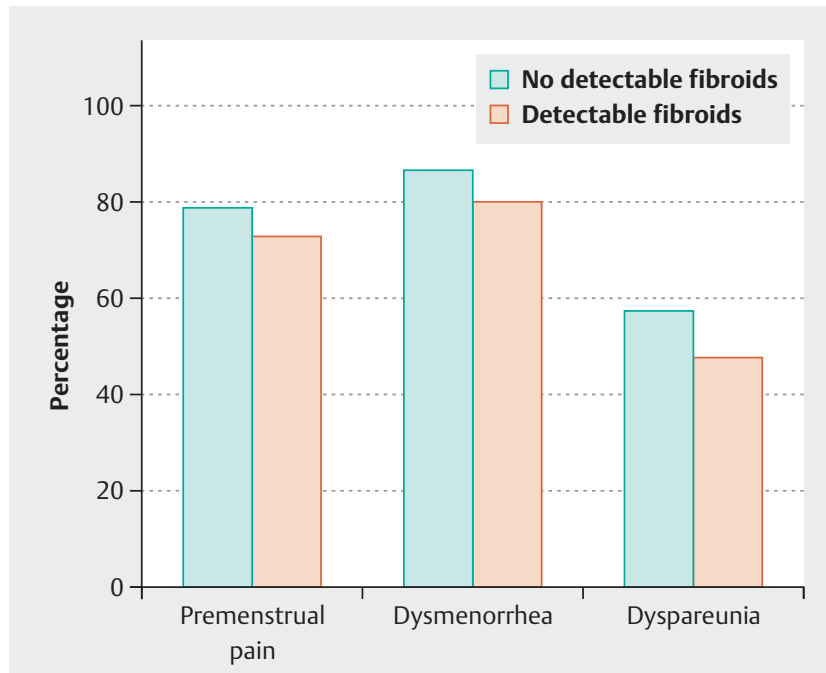

- Fig. 2 Pain reported by women with and without detectable fibroids. Levels $1-10$ have been grouped into larger groups (= symptoms of varying severity).

\section{Discussion}

Subjectivity and symptoms reported by patients which cannot be objectively verified play an important role in daily medical practice. This study has also looked at this issue and is the first study to consider the symptoms of women reporting a fibroid which could subsequently not be verified on ultrasound and compare their symptoms with those of patients with fibroids.

The patient cohort consisted of women who presented to a special fibroid clinic in a large university hospital. The information given by the women themselves about the number and size of the fibroids was subsequently verified or falsified by transvaginal (sometimes also by transabdominal) ultrasound carried out in each case by the same examiner. Ultrasound is a good method to detect fibroids and additionally provides information about the size, number and location of any fibroids $[28,29]$. The sensitivity and specificity of MRI for imaging fibroids has been reported to be comparable to that of ultrasound examinations [23]. Uterine fibroids and adenomyosis are common findings, particularly in patients with symptoms such as abnormal uterine bleeding, dysmenorrhea and dyspareunia [17]. Based on the ultrasound findings, none of our patients had adenomyosis [18].

Overall, the number of fibroids detected on ultrasound was generally in accordance with the number of fibroids reported by patients $(p=0.047)$. Only $6 \%$ of women (62 of the 1045 women included in the evaluation) were found not to have fibroids in contrast to their own assumption. In a large prospective cohort study $(n=59000$ black women, USA), Wise et al. verified the self-reported presence of myomatous uterus in $96 \%$ of cases in a subgroup of patients $(n=248)$ using ultrasound [6]. This means that the percentage of women who erroneously assumed that they had at least one fibroid in our study was roughly similar. In this particular subgroup with no detectable fibroids, $87 \%$ reported dysmenorrhea, $79 \%$ reported premenstrual pain and $57 \%$ re- ported dyspareunia, all with varying degrees of severity. No correlation was found between the described pain (dysmenorrhea, premenstrual pain, dyspareunia) and the assumed size or number of fibroids in either the group of women with or the group of women without detectable fibroids. The study by Stupin et al. $(n=498)$ showed no significant association between the number of fibroids and symptoms. But the sonographically determined size correlated with the severity of dysmenorrhea (particularly with small fibroids) $(p=0.003)$ and abdominal pressure $(p=0.02)$, while a submucosal location correlated with hypermenorrhea $(p=0,01)$ [26]. Foth et al. showed with an odds ratio of 4 that the number of fibroids had the greatest impact on the development of dysmenorrhea $(p=0,001)[30]$. Other authors have noted that women who erroneously assumed that they had many fibroids were more likely to report increased pressure on the bladder and that women who erroneously assumed that they had a particularly large fibroid were more likely to report increased abdominal pressure in contrast to few or no fibroids [6,31]. Our study found no significant difference in reported symptoms between women with detectable fibroids and those with no fibroids. The most common symptom reported by both groups of patients was dysmenorrhea. Of all three symptoms, dyspareunia was the symptom least often reported but was nevertheless reported by around half of all women with varying degrees of severity. The significant association detected between low numbers of fibroids (1-3) and frequent dyspareunia $(p=0.013)$ may also be due to the much larger number of women with 1-3 fibroids compared to the number of women with $>3$ fibroids. Patients who reported a strong pressure on the bladder or in the abdomen or strong symptoms of constipation were more likely to have a fibroid detectable on ultrasound. The opposite was the case for back pain. Dysmenorrhea and dyspareunia had no significant effect on the probability that a fibroid would be found on ultrasound. The question remains as to what the erroneous assumption of fibroids was based on in the 62 women not found to have fibroids on ultrasound. As this was a special fibroid clinic for which presenting patients required a referral from their gynecologist, all of the women evaluated in this study had previously been examined by a gynecologist. This is the probable explanation for the good overall agreement between the fibroids subjectively assumed to be present and the actual fibroid findings on ultrasound. Possible sources for the erroneous information could be insufficiently understood or insufficiently comprehensible information given to the patient or the patient's own additional research, e.g. using available internet websites or forums. The unlikely possibility that the patient was erroneously diagnosed with fibroids on ultrasound by the referring physician is of secondary importance but cannot be entirely excluded. Earlier studies showed that physicians and the internet are the most important sources of information for patients with fibroids $[5,13]$. To what extent the information that no fibroids were detectable on ultrasound was a relief and reduced patients' anxiety and ultimately led to an improvement of symptoms could not be determined in this cross-sectional study.

Of course, the reported symptoms might also be due to a different underlying disease which our examination was unable to detect. In this context it is important to be aware of the enormous complexity in the group of patients with (cyclical/non-cyclical) 
chronic pelvic pain (CPP) to which the women we investigated also belonged. It is extremely difficult to arrive at a definitive diagnosis for chronic pelvic pain. Both physical and psychosocial parameters should therefore be considered at the very start of diagnostic investigations and therapy [16]. Ultrasound findings are often normal and it is often not possible to find evidence of organ pathology [32]. CPP is a very common condition which affects around 1 out of 6 adult women [33]. It has been reported that around $10 \%$ of all gynecological consultations are for these types of symptoms; however, in more than half of the women, what causes the pain remains unclear [34]. A multimodal therapeutic approach is crucial when treating patients with CPP [16]. Ultimately, in most cases laparoscopy is the only way to definitively diagnose or exclude endometriosis $[19,20]$.

\section{Limitations}

1. All of the patients examined in this study were patients who presented to the hospital's fibroid clinic, meaning that it is not possible to make generalizations, particularly about asymptomatic patients or patients with limited symptoms.

2. The number of women in whom no fibroids were detected was relatively small $(n=62)$.

3. The study was carried out in a single center and only patients attending the hospital-based fibroid clinic were examined.

4. Abdominal pain may also be caused by early-stage adenomyosis which is not (yet) detectable on ultrasound or have other causes which can also not be detected on ultrasound, but the frequency with which such cases occur is not known.

\section{Conclusions}

These data show that it is not possible to make assumptions about the presence of fibroids, their number or size or even to suggest a therapy based on reported symptoms (dysmenorrhea, dyspareunia, premenstrual pain). Even women who erroneously assumed that they had fibroids may present with typical symptoms, which is why it is important to ensure that communications with patients are clear and coherent. Patients need to be carefully examined for other possible diseases. A further study could be carried out to investigate what patients' (erroneous) assumptions of having fibroids could be based on.

\section{Acknowledgements}

The authors would like to thank all the women who participated in the study.

\section{Conflict of Interest}

The authors declare that they have no conflict of interest.

\section{References}

[1] Wallach EE, Vlahos NF. Uterine Myomas: An Overview of Development, Clinical Features, and Management. Obstet Gynecol 2005; 105: 217

[2] Vilos GA, Allaire C, Laberge PY et al. The management of uterine leiomyomas. J Obstet Gynaecol Can 2015; 37: 157-178

[3] Williams VS, Jones G, Mauskopf J et al. Uterine fibroids: a review of health-related quality of life assessment. J Womens Health (Larchmt) 2006; 15: 818-829

[4] Nicholls C, Glover L, Pistrang N. The illness experiences of women with fibroids: an exploratory qualitative study. J Psychosom Obstet Gynaecol 2004; 25: 295-304

[5] Utz-Billing I, Rothmann K, Kentenich $\mathrm{H}$ et al. Prätherapeutische Ängste, Erwartungen, Wünsche und Informiertheit von Frauen mit Uterus myomatosus. Geburtsh Frauenheilk 2006; 66: 763-768

[6] Wise LA, Palmer JR, Stewart EA et al. Age-specific incidence rates for selfreported uterine leiomyomata in the Black Women's Health Study. Obstet Gynecol 2005; 105: 563-568

[7] Borah BJ, Nicholson WK, Bradley L et al. The impact of uterine leiomyomas: a national survey of affected women. Am J Obstet Gynecol 2013; 209: 319.e1-319.e20

[8] Khan AT, Shehmar M, Gupta JK. Uterine fibroids: current perspectives. Int J Womens Health 2014; 6: 95-114

[9] David M, Pitz CM, Mihaylova A et al. Myoma-associated pain frequency and intensity: a retrospective evaluation of 1548 myoma patients. Eur J Obstet Gynecol Reprod Biol 2016; 199: 137-140

[10] Herve F, Katty A, Isabelle Q et al. Impact of uterine fibroids on quality of life: a national cross-sectional survey. Eur J Obstet Gynecol Reprod Biol 2018; 229: 32-37

[11] Soliman AM, Margolis MK, Castelli-Haley J et al. Impact of uterine fibroid symptoms on health-related quality of life of US women: evidence from a cross-sectional survey. Curr Med Res Opin 2017; 33: 1971-1978

[12] Jones GL, Kennedy SH, Jenkinson C. Health-related quality of life measurement in women with common benign gynecologic conditions: a systematic review. Am J Obstet Gynecol 2002; 187: 501-511

[13] Knudsen NI, Wernecke KD, Siedentopf F et al. Fears and Concerns of Patients with Uterine Fibroids - a Survey of 807 Women. Geburtsh Frauenheilk 2017; 77: 976-983

[14] Ghant MS, Sengoba KS, Recht $\mathrm{H}$ et al. Beyond the physical: a qualitative assessment of the burden of symptomatic uterine fibroids on women's emotional and psychosocial health. J Psychosom Res 2015; 78: 499-503

[15] Downes E, Sikirica V, Gilabert-Estelles J et al. The burden of uterine fibroids in five European countries. Eur J Obstet Gynecol Reprod Biol 2010; 152: 96-102

[16] Chronischer Unterbauchschmerz der Frau. Quellentext zur Erstellung einer AWMF-Leitlinie der Entwicklungsstufe 2 k AWMF Online Das Portal der wissenschaftlichen Medizin 30.11.2015 [02/02/2019 10:00 am]. Online: https://www.awmf.org/uploads/tx_szleitlinien/0160011_S2k_ Chronischer_Unterbauchschmerz_Frau_2016-06.pdf; last access: 16.06.2019

[17] Shwayder J, Sakhel K. Imaging for uterine myomas and adenomyosis. J Minim Invasive Gynecol 2014; 21: 362-376

[18] Cunningham RK, Horrow MM, Smith RJ et al. Adenomyosis: A Sonographic Diagnosis. Radiographics 2018; 38: 1576-1589

[19] Moore J, Copley S, Morris J et al. A systematic review of the accuracy of ultrasound in the diagnosis of endometriosis. Ultrasound Obstet Gynecol 2002; 20: 630-634

[20] Kennedy S, Bergqvist A, Chapron C et al. ESHRE guideline for the diagnosis and treatment of endometriosis. Hum Reprod 2005; 20: 2698-2704

[21] McLucas B. Diagnosis, imaging and anatomical classification of uterine fibroids. Best Pract Res Clin Obstet Gynaecol 2008; 22: 627-642 
[22] Testa AC, Di Legge A, Bonatti M et al. Imaging techniques for evaluation of uterine myomas. Best Pract Res Clin Obstet Gynaecol 2016; 34: 37-53

[23] Dueholm M, Lundorf E, Hansen ES et al. Accuracy of magnetic resonance imaging and transvaginal ultrasonography in the diagnosis, mapping, and measurement of uterine myomas. Am J Obstet Gynecol 2002; 186: 409-415

[24] Vercellini P, Cortesi I, Oldani S et al. The role of transvaginal ultrasonography and outpatient diagnostic hysteroscopy in the evaluation of patients with menorrhagia. Hum Reprod 1997; 12: 1768-1771

[25] Dijkhuizen FP, Brolmann HA, Potters AE et al. The accuracy of transvaginal ultrasonography in the diagnosis of endometrial abnormalities. Obstet Gynecol 1996; 87: 345-349

[26] Stupin JH, Rothmann K, Kentenich $\mathrm{H}$ et al. [Correlation between sonographic findings and level of knowledge/self-report of symptoms in women with uterine leiomyomata]. Ultraschall in der Medizin 2011; 32 (Suppl. 2): E86-E91

[27] Berlin C-U. Neufassung der Satzung der Charité - Universitätsmedizin Berlin zur Sicherung Guter Wissenschaftlicher Praxis vom 20.06.2012 (AMB Charité Nr.092, S.658) 29.03.2018 [2/2/2019; 10:00 am]. Online: https://www.charite.de/fileadmin/user_upload/portal/charite/ presse/publikationen/amtl-mitteilungsblatt/2018/AMB180329-208.pdf; last access: 16.06.2019
[28] Farquhar C, Ekeroma A, Furness S et al. A systematic review of transvaginal ultrasonography, sonohysterography and hysteroscopy for the investigation of abnormal uterine bleeding in premenopausal women. Acta Obstet Gynecol Scand 2003; 82: 493-504

[29] Griffin KW, Ellis MR, Wilder L et al. Clinical inquiries. What is the appropriate diagnostic evaluation of fibroids? J Fam Pract 2005; 54: 458, 460, 462

[30] Foth D, Rohl FW, Friedrich C et al. Symptoms of uterine myomas: data of an epidemiological study in Germany. Arch Gynecol Obstet 2017; 295: 415-426

[31] Spies JB, Coyne K, Guaou Guaou N et al. The UFS-QOL, a new diseasespecific symptom and health-related quality of life questionnaire for leiomyomata. Obstet Gynecol 2002; 99: 290-300

[32] Siedentopf F, Sillem M. [Chronic pelvic pain in women]. Schmerz 2014: 28: 300-304

[33] Zondervan KT, Yudkin PL, Vessey MP et al. The community prevalence of chronic pelvic pain in women and associated illness behaviour. $\mathrm{Br}$ J Gen Pract 2001; 51: 541-547

[34] Mathias SD, Kuppermann M, Liberman RF et al. Chronic pelvic pain: prevalence, health-related quality of life, and economic correlates. Obstet Gynecol 1996; 87: 321-327 